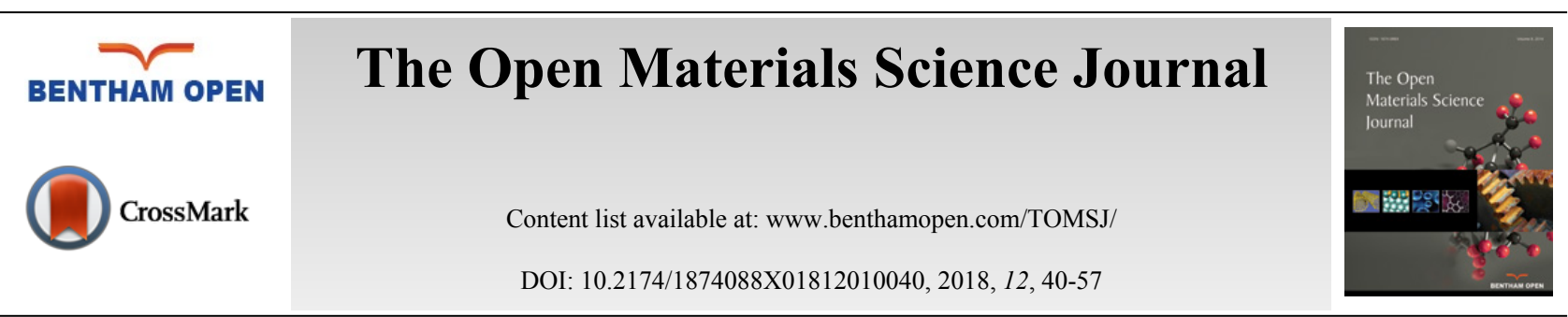

RESEARCH ARTICLE

\title{
Optimization of Slag Content and Properties Improvement of Metakaolin-slag Geopolymer Mixes
}

\author{
M. F. Zawrah", R. A. Gado and R. M. Khattab \\ National Research Centre, Ceramics Department-Center of Excellence for Advanced Sciences, 12622-Dokki, Cairo, \\ Egypt
}

Received: April 4, 2018

Revised: June 12, 2018

Accepted: June 20, 2018

\begin{abstract}
:
object:

Geopolymers mixes were fabricated from Metakaolin (MK) and Blast Furnace Slag (BFS) waste material in the presence of sodium hydroxide and sodium silicate which were used as alkali activators. To optimize the suitable amount of slag, eleven batches were designed, mixed and homogenized for $30 \mathrm{~min}$.
\end{abstract}

\section{Method:}

To determine the suitable amount of liquid required for pasting, normal consistency and setting time were determined. The physicomechanical properties at different curing ages i.e. 3, 7, 28 and 90 days, were determined. X-ray diffraction and scanning electron microscope were used to investigate phase composition and microstructure.

\section{Result:}

To guarantee forming geopolymer gel and to check its amount, $\mathrm{HCl}$ extraction test was performed. Salicylic acid/methanol extraction was also performed to verify the presence and amount of Calcium Silicate Hydrate (CSH). The results revealed that calcium-rich slag (BFS) accelerated the hardening process and decreased the alkaline liquid consistency. For geopolymer without BFS, two phases, namely; un-reacted metakaolin and geopolymer gel were formed. For geopolymers with BFS, three phases were formed, namely; unreacted metakaolin, geopolymer gel and CSH with aluminum substitution (CASH) gel. The bulk density was increased with increasing BFS and curing time. The strength was increased with increasing of BFS, reaching its maximum (about $120 \mathrm{MPa}$ ) for the specimen containing $70 \%$ slag, cured for 28 days.

Keywords: Geopolymer, Metakaolin, Slag, Properties, Calcium Silicate Hydrate (CSH), X-ray.

\section{INTRODUCTION}

Recently, new type of un-fired ceramic materials has received attention. This material often refers to geopolymer or inorganic polymer. At the end of 1970 s, geopolymer has been identified and used by J. Davidovits. Recently, geopolmer known as alkali activated aluminosilicate binders with the general formula $\mathrm{M}_{2} \mathrm{O} \cdot \mathrm{mAl}_{2} \mathrm{O}_{3} \cdot \mathrm{nSiO}_{2}, \mathrm{where} \mathrm{m} \approx 1$ and $2 \leq \mathrm{n} \leq 6$ (M usually is $\mathrm{Na}$ or $\mathrm{K}$ ) [1]. It forms by the reaction of an aluminosilicate material with highly concentrated alkaline solution [2]. The presence of higher amounts of $\mathrm{Al}$ and $\mathrm{Si}$ causes re-condensation of soluble ions which consequently assemble into inorganic polymer and create amorphous network with high mechanical strength compared with other binding materials. In this polymerization process, water doesn't consume for hydration; it has an active role as a dissolution medium. The alkali ions in the medium are connected in geoplymer network through balancing with $\mathrm{Al}$ and $\mathrm{Si}[3]$.

\footnotetext{
* Address for correspondence to this auther at the National Research Centre, Ceramics Department-Center of Excellence for Advanced Sciences,
} 12622-Dokki, Cairo, Egypt, Tel: +201222437949, Fax: +20233370931; E-mail: mzawrah@hotmail.com 
Generally, geopolymer can be prepared at ambient or elevated temperature using alumino-silicates. There are many sources of geoplymer starting materials to be used mixed or as individuals; such as waste materials, kaolin, pozolanic materials, melt quenched aluminum silicates and volcanic scoria [4 - 8]. It has several important applications as binding materials, advanced ceramics, fire retardant materials, high technological materials, and stabilizer for hazardous materials [9].

Geopolymerization proceeds through dissolution, polymerization, reorganization and hardening [10]. In highly concentrated alkaline aqueous solution, aluminum silicates are quickly dissolved to form free $\mathrm{SiO}_{4}$ and $\mathrm{AlO}_{4}$ tetrahedral units freely distributed in the medium. During progressing of reaction, $\mathrm{H}_{2} \mathrm{O}$ comes apart and the formed tetrahedral units are connected alternatively by sharing all oxygen atoms to give three kinds of geopolymers; (a) poly-sialate [-SiO ${ }_{4}^{-}$ $\left.\mathrm{AlO}_{4^{-}}\right]$(PS type), (b) poly-sialate-siloxo [- $\left.\mathrm{SiO}_{4}-\mathrm{AlO}_{4}-\mathrm{SiO}_{4^{-}}\right]$(PSS type), or (c) polysialate- disiloxo [- $\mathrm{SiO}_{4}-\mathrm{AlO}_{4}-\mathrm{SiO}_{4}^{-}$ $\mathrm{SiO}_{4^{-}}$(PSDS type). This means that $\mathrm{Si}: \mathrm{Al}$ ratios in the three types are $\mathrm{Si}: \mathrm{Al}=1$ for sialate (-Si-O-Al-O-), $\mathrm{Si}: \mathrm{Al}=2 \mathrm{for}$ sialate siloxo (-Si-O-Si-Al-O), $\mathrm{Si}: \mathrm{Al}=3$ for sialate-disiloxo (-Si-O-Al-O-Si-O-Si-) and $\mathrm{Si}: \mathrm{Al}>3$ when it is poly ( multisiloxo) [11]. After hardening, the materials have excellent compressive strength, compactness, durability and anticorrosion [12]. There are many natural or waste sources such as fly ash and blast furnace slag that contain calcium ions and can be used in geoploymer fabrication. Calcium can play important role in geopolymer; it can make the system to undergo two separate and competing reactions. The first one is the formation of geopolymer while the second is the formation of calcium silicate hydrate or calcium aluminum silicate hydrate (CASH). This means that the presence of calcium raises the strength of geopolymer cured at ambient condition, while it decreases the strength of geopolymer treated at elevated temperature. This is due to that the presence of calcium hinders the formation of 3D network structure in geopolymer gel $[13,14]$. However, previous study reported the presence of both calcium silicate hydrate and geopolymer gel in the matrix have valuable effects on the mechanical properties since it acts as micro-aggregates in geopolymer gel and forms a denser and more uniform binder [15].

In comparison with normal cement, geopolymer has lower energy consumption and $\mathrm{CO}_{2}$ emission, good physicomechanical properties as strength, shrinkage, permeability, durability, and has good resistance for fire and acids [16, $17]$.

Blast furnace slag is a by-product material produced from iron blast furnace after quenching in water or air. It composed mainly from $\mathrm{CaO}-\mathrm{SiO}_{2}-\mathrm{MgO}-\mathrm{Al}_{2} \mathrm{O}_{3}$ oxides and can form the mixture of following phases: gehlenite $\left(2 \mathrm{CaO} \cdot \mathrm{Al}_{2} \mathrm{O}_{3} \cdot \mathrm{SiO}_{2}\right)$ and akermanite $\left(2 \mathrm{CaO} \cdot \mathrm{MgO} \cdot 2 \mathrm{SiO}_{2}\right)$, and de-polymerized calcium aluminum silicate glass. Previous study by Yip et al. reported the influence of slag addition on metakaolin geopolymer [18].

The purpose of this article is to study the influence of BFS addition (up to 100\%) on geopolymerization reaction of metakaolin-based geopolymer at room temperature. The optimum amount of slag to give improved properties was identified. The produced geopolymers were investigated for their physico-mechanical properties, salicylic acid/methanol (SAM) extraction, hydrochloric acid $(\mathrm{HCl})$ extraction, X-ray diffraction, FTIR and SEM.

\section{EXPERIMENTAL METHODS}

\subsection{Starting Materials}

Kaolin was supplied from general company for ceramic \& porcelain products (Sheeni), Egypt. Metakaolin (MK) was prepared by calcination of kaolin at $850^{\circ} \mathrm{C}$ for 3 hours in a furnace with heating rate of $5^{\circ} \mathrm{C} / \mathrm{min}$ then milled in planetary ball mill for $30 \mathrm{~min}$ to produce MK powder having Blaine specific surface area of $2,120 \mathrm{~m} / \mathrm{kg}$ and specific gravity of $2500 \mathrm{~kg} / \mathrm{m}^{3}$. BFS used in this study, is water cooled slag supplied from Iron and Steel Factory, Helwan, Egypt. The slag was firstly ground in laboratory ball mill for 3 hours to obtain Blaine specific surface area of $610 \mathrm{~m}^{2} / \mathrm{kg}$ with specific gravity of $3000 \mathrm{~kg} / \mathrm{m}^{3}$. The chemical composition of MK and BFS was determined by X-ray fluorescence. The particle size distribution of MK and BFS was determined through laser granulometry. The mineral phases were identified by XRD using Philips D-Expert, Netherlands, diffractometer with Ni filter, $\mathrm{Cu}$ Ka radiation at scan speed of $0.5^{\circ} \mathrm{min}^{-1}$. FTIR was conducted for starting materials using JASCO FT/IR-6100. The spectrum was recorded between 400 and $4000 \mathrm{~cm}^{-1}$ with resolution of $4 \mathrm{~cm}^{-1}$ at $25^{\circ} \mathrm{C}$.

$\mathrm{NaOH}$ pellet (98\% purity) was supplied from Sigma. 10 molar $\mathrm{NaOH}$ solution was prepared and kept to cool down at room temperature before preparing of the pastes. Sodium silicate solution was purchased from Fisher scientific, UK., with chemical composition of $30.1 \% \mathrm{SiO}_{2}, 9.4 \% \mathrm{Na}_{2} \mathrm{O}$ and $60.5 \% \mathrm{H}_{2} \mathrm{O}$ (silicate modulus, $\mathrm{SiO}_{2} / \mathrm{Na}_{2} \mathrm{O}=3.2$ ), specific gravity at $20^{\circ} \mathrm{C}=1.5 \mathrm{~g} / \mathrm{ml}$. Alkali activator solution was prepared by mixing sodium silicate solution and $\mathrm{NaOH}(10 \mathrm{M})$ 
solution by 1:1 ratio, and left until clear solution obtained. This solution was prepared for minimum $24 \mathrm{~h}$ before preparation of pastes to allow its equilibration [19, 20].

\subsection{Geopolymer Preparation}

Several batches composed of metakaolin MK and BFS were designed, mixed and homogenized for 30 min by ball mill as illustrated in (Table 1).

Table 1. Designed geopolymer mixes.

\begin{tabular}{|c|c|c|c|c|c|c|c|c|c|c|c|}
\hline Mixes & $\mathbf{G}$ & $\mathbf{G}_{1}$ & $\mathbf{G}_{2}$ & $\mathbf{G}_{\mathbf{3}}$ & $\mathbf{G}_{4}$ & $\mathbf{G}_{\mathbf{5}}$ & $\mathbf{G}_{6}$ & $\mathbf{G}_{7}$ & $\mathbf{G}_{\mathbf{8}}$ & $\mathbf{G}_{9}$ & $\mathbf{G}_{\mathbf{1 0}}$ \\
\hline MK & $\mathbf{1 0 0}$ & $\mathbf{9 0}$ & $\mathbf{8 0}$ & $\mathbf{7 0}$ & $\mathbf{6 0}$ & $\mathbf{5 0}$ & $\mathbf{4 0}$ & $\mathbf{3 0}$ & $\mathbf{2 0}$ & $\mathbf{1 0}$ & $\mathbf{0}$ \\
\hline GGBFS & $\mathbf{0}$ & $\mathbf{1 0}$ & $\mathbf{2 0}$ & $\mathbf{3 0}$ & $\mathbf{4 0}$ & $\mathbf{5 0}$ & $\mathbf{6 0}$ & $\mathbf{7 0}$ & $\mathbf{8 0}$ & $\mathbf{9 0}$ & $\mathbf{1 0 0}$ \\
\hline Total, $\%$ & $\mathbf{1 0 0}$ & $\mathbf{1 0 0}$ & $\mathbf{1 0 0}$ & $\mathbf{1 0 0}$ & $\mathbf{1 0 0}$ & $\mathbf{1 0 0}$ & $\mathbf{1 0 0}$ & $\mathbf{1 0 0}$ & $\mathbf{1 0 0}$ & $\mathbf{1 0 0}$ & $\mathbf{1 0 0}$ \\
\hline
\end{tabular}

To determine the suitable amount of liquids needed for mixing, normal consistency and setting time were determined using Humboldt Vicat's apparatus [21, 22]. Here, alkaline solution was used instead of water. To prepare geopolymer pastes, the required alkali activator solution of predetermined normal consistency [ASTM: C 187 - 1998] was added to the mixes depending on the proportions of mixes ingredients. To ensure good adherence among mix ingredients, the mixing operation was then completed by continuous vigorous mixing for about ten minutes by hand. The fresh mixes pastes were poured in plastic cubical moulds with $25 \times 25 \mathrm{~mm}$ dimensions then vibrated on vibrating table for period of 1-2 minutes to remove any air bubbles to give better compacted paste. The surface of paste was smoothed by the aid of thin edged trowel. Then the mould covered by plastic thin film to prevent excessive moisture loss and kept within humidity chamber at $100 \%$ relative humidity at constant temperature of $23 \pm 2{ }^{\circ} \mathrm{C}$ for the first 24 hours. The prepared cubes were de-molded and left at ambient temperature. All samples were cured at atmospheric pressure and no attempt was made to control the humidity during curing under ambient laboratory conditions (dry cured).

\subsection{Geopolymer Characterization}

Physico-mechanical properties at different curing ages i.e. 3, 7, 28 and 90 days were determined. Three samples of each mix were randomly selected to determine bulk density, apparent porosity, water absorption and compressive strength according to [ASTM C 20=2000] and [ASTM: C109]. Bulk density, apparent porosity and water absorption were determined by water displacement method according to Archimedes principle. The compressive strength was carried out using automatic hydraulic testing machine type SHIMADZU of maximum capacity $1000 \mathrm{KN}$ by rate of $0.025 \mathrm{KN} / \mathrm{mm}^{2} / \mathrm{s}$. To ensure forming geopolymer gel and to monitor the amount of formed geopolymer gel through alkaline activation, hydrochloric $(\mathrm{HCl})$ acid extraction test was performed [23, 24]. Salicylic acid/methanol (SAM) extraction was also performed to verify the presence and amount of CSH. The extraction process leaves only the unreacted precursors. When these methods are performed, it is possible to determine how much geopolymer, CSH and unreacted material are present. XRD, FTIR and scanning electron microscopy (SEM-JEOL Ltd., Japan) attached with EDX unit were used to investigate phase and structure composition as well as microstructure of the obtained geopolymers.

\section{RESULTS AND DISCUSSION}

\subsection{Starting Material Characteristics}

The chemical analysis of MK and BFS analyzed by $\mathrm{x}$-ray fluorescence is illustrated in Table 2. It is indicated that the main components of $\mathrm{MK}$ are silica and alumina. The basicity coefficient $\left(\mathrm{Kb}=\mathrm{CaO}+\mathrm{MgO} / \mathrm{SiO}_{2}+\mathrm{Al}_{2} \mathrm{O}_{3}\right)$ and the quality coefficient $\left(\mathrm{CaO}+\mathrm{MgO}+\mathrm{Al}_{2} \mathrm{O}_{3} / \mathrm{SiO}_{2}+\mathrm{TiO}_{2}\right)$ calculated for BFS are 1.48 and 2.13, respectively. The particles size range of $\mathrm{MK}$ and $\mathrm{BFS}$ are $\mathrm{d} 50 \approx 400$ and $\approx 800 \mathrm{~nm}$, respectively as shown in (Fig. 1).

Table 2. Chemical composition of starting materials.

\begin{tabular}{|c|c|c|c|c|c|c|c|c|c|c|c|c|}
\hline Main Oxides & $\mathrm{SiO}_{2}$ & $\mathrm{Al}_{2} \mathrm{O}_{3}$ & $\mathrm{Fe}_{2} \mathrm{O}_{3}$ & $\mathrm{CaO}$ & $\mathrm{Na}_{2} \mathrm{O}$ & $\mathrm{K}_{2} \mathrm{O}$ & $\mathrm{TiO}_{2}$ & $\mathrm{MnO}$ & $\mathrm{MgO}$ & $\mathrm{SO}_{3}$ & $\mathrm{BaO}^{2}$ & $\mathrm{L.O.I}$ \\
\hline $\mathrm{MK}$ & 46.68 & 35.75 & 1.49 & 0.10 & 0.05 & 2.96 & 0.07 & 0.01 & 0.19 & 0.03 & 0.02 & 12.18 \\
\hline GBFS & 26.15 & 7.43 & 1.31 & 44.38 & 0.75 & 0.53 & 0.68 & 5.25 & 5.52 & 2.90 & 4.72 & --- \\
\hline
\end{tabular}


XRD analyses of kaolin, MK and BFS are shown in Fig. (2). It indicated that the kaolin exhibits typical diffraction pattern of well crystallized layer lattice of kaolinite with muscovite impurities (illite mineral). Transformation of kaolin to metakaolin is detected after calcination at $850^{\circ} \mathrm{C}$. The calcination leads to break down of the crystal structure, producing amorphous or semi crystalline phases (silica and alumina in reactive form). The characteristic peaks for kaolinite at $2 \theta=12.34,20.34,24.87$ and 26.40 are disappeared, while another weak peaks assigned to quartz at $2 \theta$ $=20.83$ and 26.64); Illite at $2 \theta=9.11$ and 15.91 remained in metakaolin pattern [25]. XRD of BFS shows halo hump between $2 \theta=20-40$, indicating the amorphous nature of material with some semi crystalline phases such as merwinite and melilite. Merwinite has the composition $2 \mathrm{CaO} \cdot \mathrm{Al}_{2} \mathrm{O}_{3} \cdot \mathrm{SiO}_{2}$; while melilite is solid solution series between gehlenite $\left(2 \mathrm{CaO} \cdot \mathrm{Al}_{2} \mathrm{O}_{3} \cdot \mathrm{SiO}_{2}\right)$ and akermanite $\left(2 \mathrm{CaO} \cdot \mathrm{MgO} \cdot 3 \mathrm{SiO}_{2}\right)$. The unusual crystallinity of slag comes always from its quenching during production. For the supplied slag in the present study, it was not rapidly quenched in water or air, but during its transportation, it was gradually cooled at ambient temperature and then quenched in water [26].

(A)

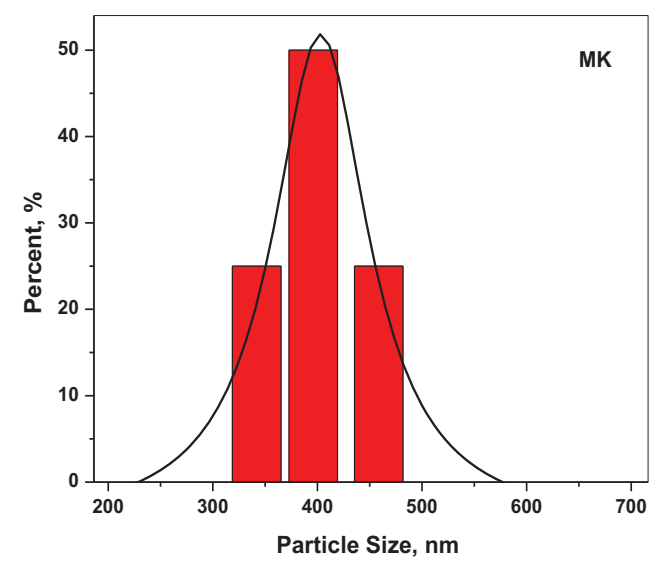

(B)

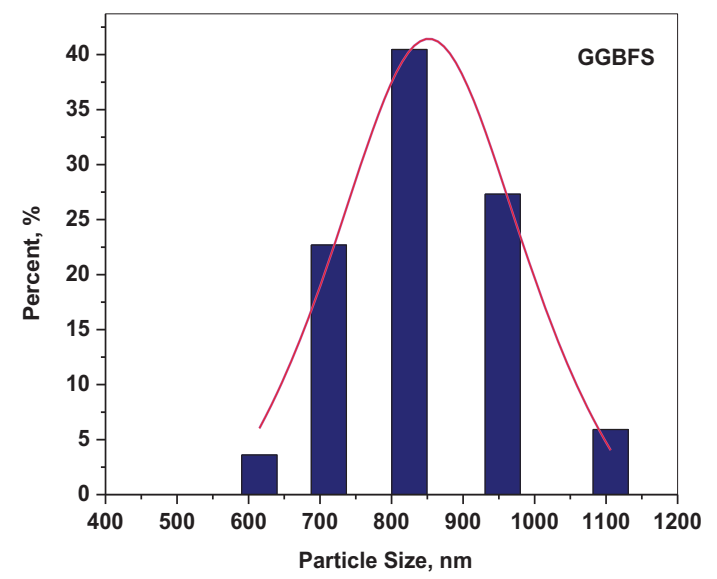

Fig. (1). Particle size distribution of Metakaolin (a) and BFS (b).
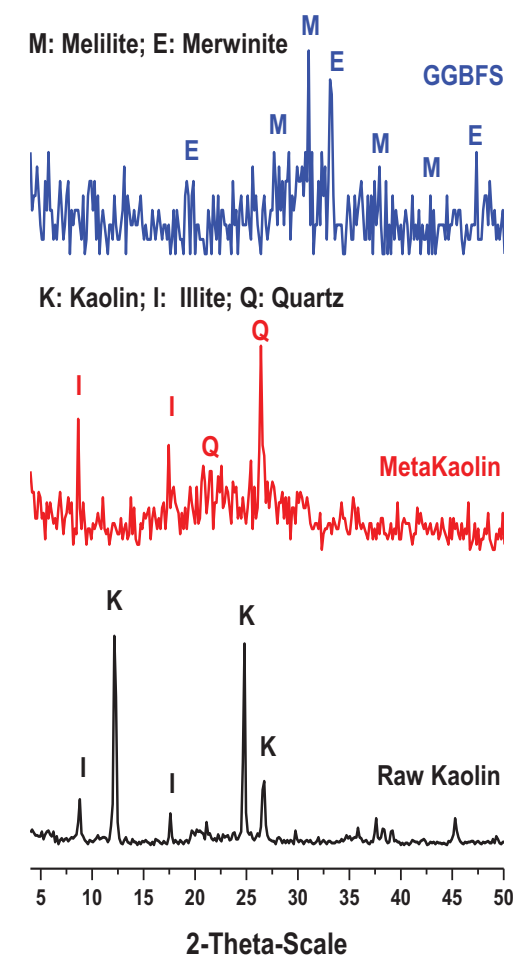

Fig. (2). XRD patterns of starting materials. 
IR spectra of kaolin, MK and BFS are shown in Fig. (3). A characteristic spectrum of kaolin bands at 3695 and 3620 $\mathrm{cm}^{-1}$ are appeared which ascribed to the vibration of external hydroxyl and inner hydroxyl, respectively. The bands indicated at 3455 and $1630 \mathrm{~cm}^{-1}$ could be assigned to $\mathrm{OH}$ vibrational mode of hydroxyl molecule in water, which is observed in almost all natural hydrous silicates. The band at $1033 \mathrm{~cm}^{-1}$ is for the main functional Si-O group. Muscovite and possibly quartz interference could be observed at $1031-1038 \mathrm{~cm}^{-1}$ for kaolin. Al-OH peak is identified at $912 \mathrm{~cm}^{-1}$. The doublet at 754-789 $\mathrm{cm}^{-1}$ is due to Si-O-Si inter tetrahedral bridging bonds in $\mathrm{SiO}_{2}$ and $\mathrm{OH}$ deformation band. The spectra of kaolin exhibit Si-O stretching vibrations at 754, 697 and $467 \mathrm{~cm}^{-1}$ which are indicative of the presence of quartz [27]. The spectrum of MK exhibits main broad band at $1065 \mathrm{~cm}^{-1}$ which ascribed to disorder induced by dehydroxylation process of kaolin and formation of amorphous structures. Reduction in bands observed at 3433 and 1628 $\mathrm{cm}^{-1}$, was assigned to the $\mathrm{OH}$ vibrational mode of hydroxyl molecule in water. The vibration mode at $807 \mathrm{~cm}^{-1}$ is associated with $\mathrm{Al}-\mathrm{O}$ bonds of tetrahedral $\mathrm{Al}$, while $\mathrm{Si}-\mathrm{O}$ bending vibration at about $472 \mathrm{~cm}^{-1}$ is also detected [28].
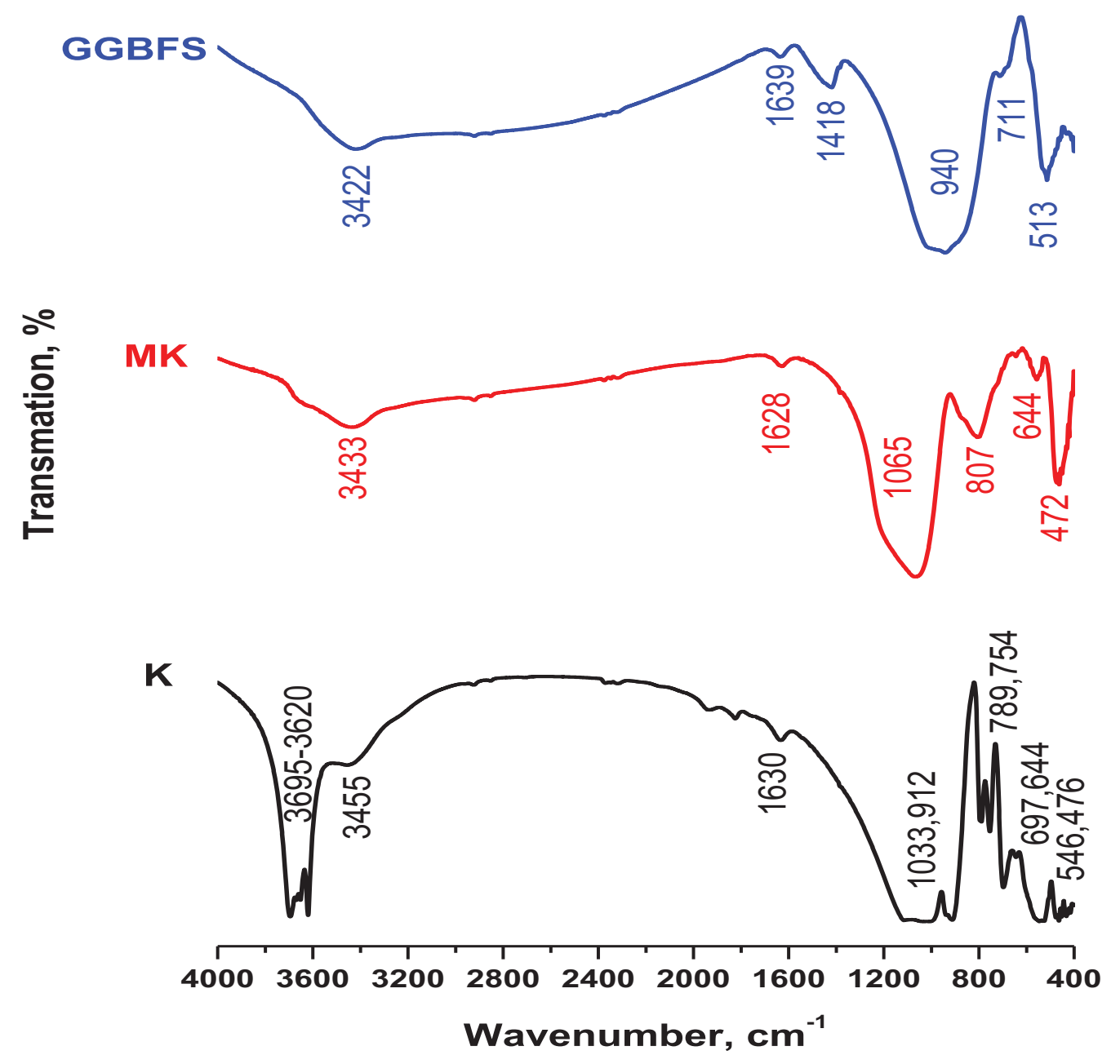

Fig. (3). FTIR of starting materials.

The spectrum of BFS shows broad vibration modes at $940 \mathrm{~cm}-1$ which is characteristic of T-O (where $\mathrm{T}$ is $\mathrm{Si}$ or $\mathrm{Al}$ ) bonds of tetrahedral silicates. The band at $711 \mathrm{~cm}^{-1}$ is attributed to the bending vibration mode of Al-O-Si bonds. These two bands are also corresponding to gehlenite [29], which has been confirmed by X-ray diffraction. The band at 1418 $\mathrm{cm}^{-1}$ is assigned to asymmetric vibration mode of $\mathrm{O}-\mathrm{C}-\mathrm{O}$ bonds in carbonates. This confirms the partial carbonation identified in raw material due to the weathering during storage [30].

\subsection{Alkaline Liquid Consistency and Setting Time of Geopolymer Pastes}

The normal consistency and setting time are important parameters in practice for cementitious material pastes for workability determination. The normal consistency determines the optimum percentage of liquid/solid ratio to form 
paste suitable for shaping [31,32]. The results of normal consistency and setting time are given in Fig. (4). The main factors affecting geopolymer setting time are chemical and phase compositions of raw materials, properties of alkaline activators, solid loading, fineness of solids and curing temperature [33 - 35]. The addtion of calcium-rich BFS to MK based geopolymers causes improvement and shorting in setting time of geopolymer by forming calcium aluminum silicate hydrate (CASH) gel in addition to the sodium aluminum silicate hydrate (NASH) gel (geopolymer gel) [36, 37] with compact microstructure [38]. BFS accelerates the hardening process and decreases the alkaline liquid consistency. This is related to the formation of higher yield stress in gel structure and thus is markedly influenced by increasing the rate of crosslinking [39].

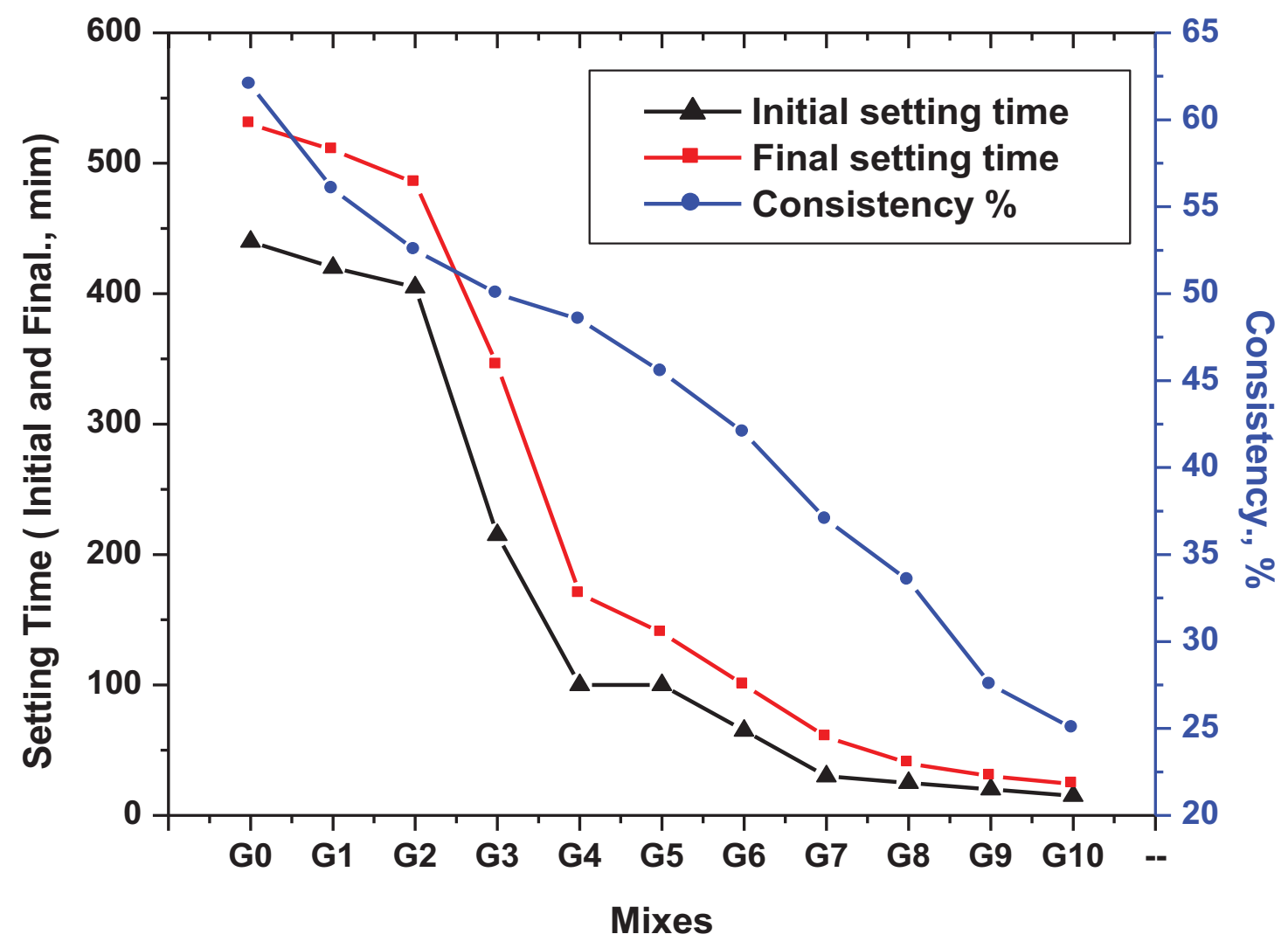

Fig. (4). Normal consistency and setting times of prepared mixes.

In metakaolin-slag geopolymer, two mechanisms have been reported for the alkali activated binding geopolymers; the first one is slag activation $(\mathrm{Si}+\mathrm{Ca})$ with gentle alkaline medium leading to $\mathrm{CSH}$ as the main reaction products. The second one is the alkali activation of metakaolin $(\mathrm{Si}+\mathrm{Al})$ with medium to high alkaline media. They can form zeolite like polymers (gel structure). It has been reported by Davidovits that the second groups are considered as "Geopolymer" since they have polymeric structure [40, 41].

\subsection{Geopolymer Characterization}

\subsubsection{Physico-mechanical Properties}

The physico-mechanical properties in terms of bulk density, apparent porosity, water absorption and compressive strength of metakaolin-slag geopolymers prepared at different curing ages are given in Fig. (5). As indicated, by increasing BFS content in the mixes, the bulk density increases from $1.67-2.33 \mathrm{~g} / \mathrm{cm}^{3}$ Fig. (5a). Moreover, the bulk density increases with increasing curing time. As a result of adding BFS in geopolymer system, different chemical reactions which lead to different products are occurred. This leads to different bulk density and thus higher compressive strength is achieved. On the other hand, with increasing BFS content, the porosity and water absorption are decreased as illustrated in Figs. $(\mathbf{5 b}, \mathbf{c})$. This is due to the formation of CASH with geopolymer network. Moreover, the water 
absorption which depends on the microstructure and porosity of the specimens is decreased with increasing curing time. Water absorption is considered as an indicator for the degree of geopolymeric reaction. The compressive strength Fig. (5d) increases with increasing slag content and curing time reaching its maximum value with batch G7 (118MPa after 28 day) after which its value decreases. The results of compressive strength after 28 days curing are relatively similar to that after 90 days curing. The strength variation implies that there are changes in gel content and reaction nature between the mixes which takes place leading to microstructural changes induced in geopolymers when BFS is substituted for metakaolin. With increasing the dosage of BFS to $80 \%$ (G8), deterioration in compressive strength is obtained. The compressive strengths of the geopolymer with 60 and 70wt.-\% BFS are 93 and $118 \mathrm{MPa}$, respectively, while those with $80 \mathrm{wt},-\%$, and $90 \mathrm{wt} \%$ are 77 and $58 \mathrm{MPa}$, respectively. The compressive strength of MK-based geopolymer is $43 \mathrm{MPa}$ which is less than half that of G7; by other word, G7 exhibits approximately a tripling in compressive strength as compared with MK-based sample (G0). This is attributed to the reaction of Ca supplied by BFS with some excess to silicates present to form additional strength-giving gel i.e. Ca ion plays the key role in geopolymer skeleton. In fact, the high $\mathrm{CaO}$ content effects in quicker geopolymerization and development of semi-crystalline CaAl-Si hydrate gel produced from reaction between calcium silicate hydrate $(\mathrm{CSH})$ and aluminosilicate group strengthen the network $[42,43]$.

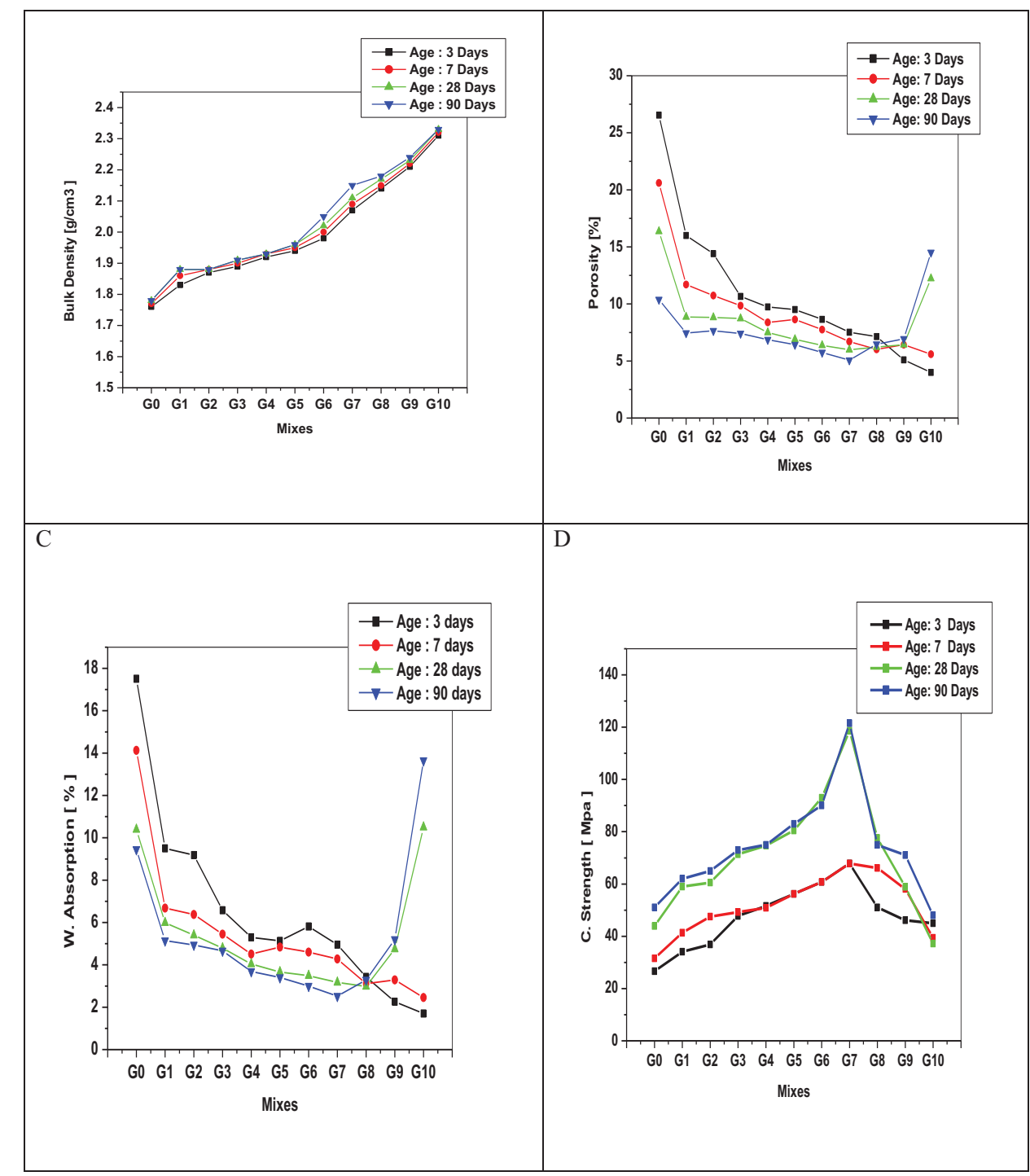

Fig. (5). Physico-mechanical properties of geopolymers. 
Before testing the compressive strength, the samples were inspected visually for any potential crack. They were fairly good and no crack was observed visually for the samples G0 until G7. As seen in Fig. (6), the samples contain more than $70 \%$ BFS exhibit cracks which reflected negatively on physical and mechanical properties of specimens. This is supposed to be due to the volume changes that could happen when forming an amorphous to semi-crystalline CSH gel inside an incompletely hardened geopolymer gel.
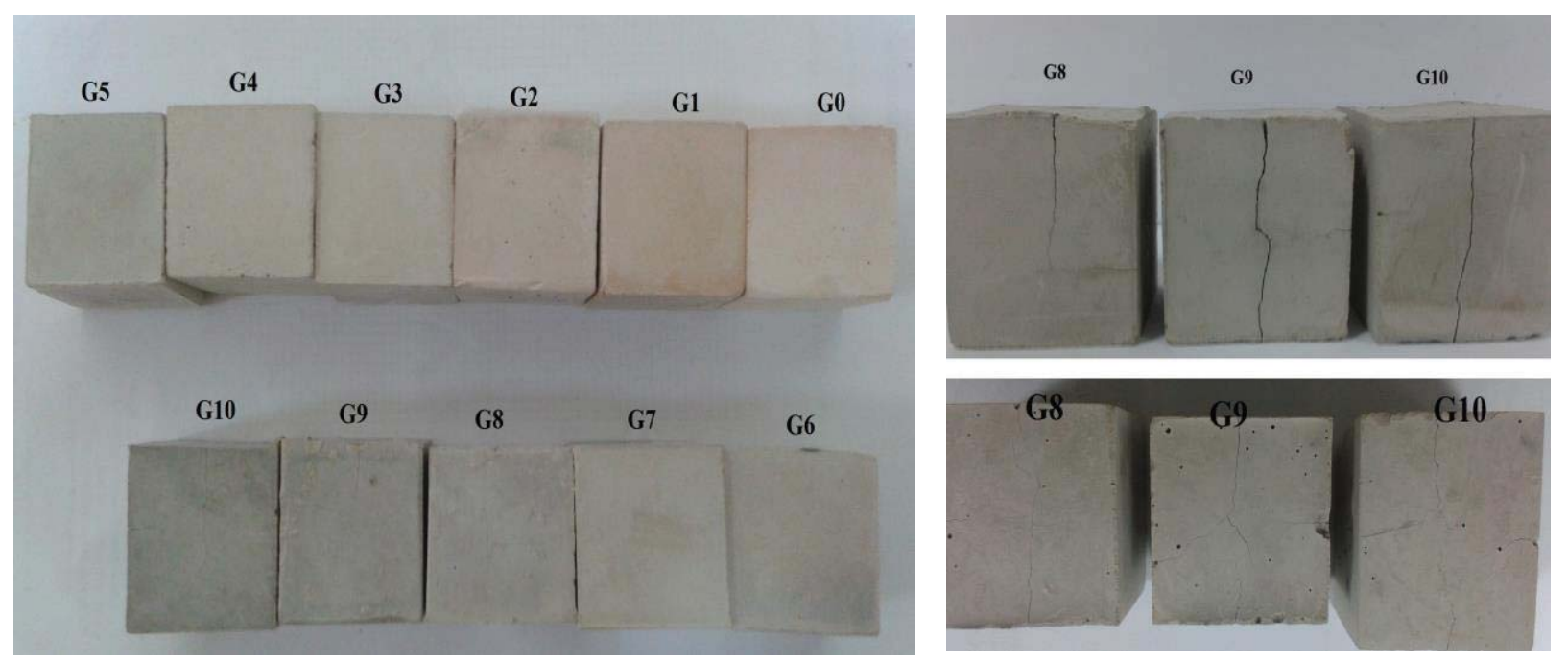

Fig. (6). Images of metakaolin-slag geopolymer specimens after curing in air.

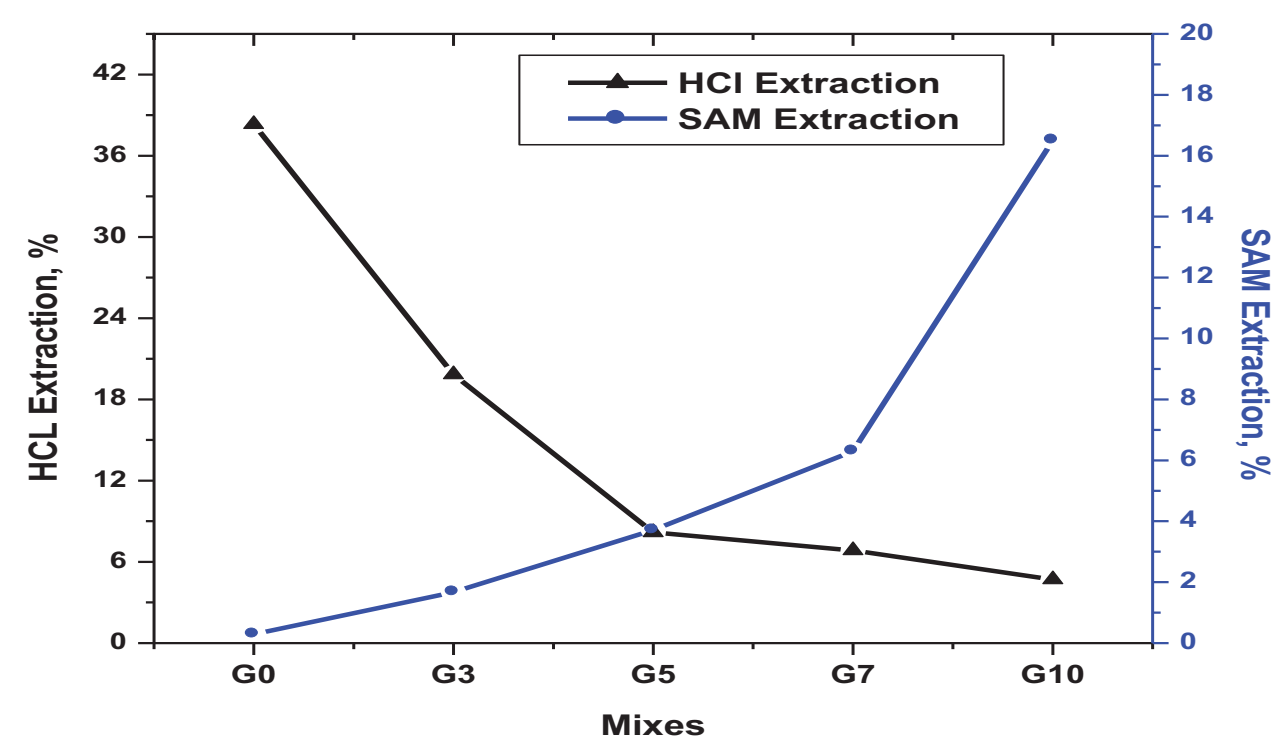

Fig. (7). $\mathrm{HCl} \& \mathrm{SAM}$ extractions of geopolymers.

The prepared geopolymers contain two or three phases depending on whether BFS is used or not. For geopolymer with no BFS (G0), it contains two phases, namely; un-reacted metakaolin and geopolymer gel. For geopolymers with calcium oxide sourced from BFS (G1-G10), the samples contain three phases, namely; un-reacted metakaolin, geopolymer gel and CSH with CASH [44]. Fig. (7) depicts the results of $\mathrm{HCl}$ and SAM extractions for G0, G3, G5, G7 and $\mathrm{G10}$ geopolymers. $\mathrm{HCl}$ dissolves geopolymer gel and $\mathrm{CSH}$ reaction products and leaves un-reacted metakaolin. As shown in Fig. (7), $\mathrm{HCl}$ extraction results show that G0 retains more un-reacted material as compared with other geopolymers containing BFS (G1-G10). The amount of un-reacted metakaolin remained in geopolymer is $38 \%$. This is due to incomplete geopolymerization process. The amount of un-reacted metakaolin remained after $\mathrm{HCl}$ extraction decreases as the BFS\% increases which indicates increasing the acceleration rate of geopolymerization process. As indicted in Fig. (7), SAM extraction results show that geopolymer with $0 \%$ BFS does not have any CSH phases. The 
$\mathrm{CSH}$ phases in matrix increases as the BFS increases which indicates the formation of new CSH phases in associated with geopolymer products as a result of the presence of $\mathrm{CaO}$. The amount of CSH type phases in $\mathrm{G} 10$ matrix is $16 \%$ which may be due to alkali activation process for BFS only. SAM extraction results are correlated well with the result of XRD which shows low intensity for CSH phases formed in geopolymer samples G3-G7.

\subsubsection{XRD of Geopolymers}

XRD patterns of $\mathrm{G}, \mathrm{G}_{3}, \mathrm{G}_{5}, \mathrm{G}_{7}$ and $\mathrm{G}_{10}$ geopolymers aged for 28 days are shown in Fig. (8). It worthy to mention that most of geopolymer binders produced in this study contain a very high percentage of amorphous or few semicrystalline phases. The major phase of geopolymer samples $\left(\mathrm{G}-\mathrm{G}_{7}\right)$ is amorphous as indicated by the broad hump at $2 \theta=20-40$. The amorphous phase (Na-ASH) is obtained from dissolution of kaolinite particle in alkaline activator and then reconstruction of $\mathrm{AlO}_{4}$ and $\mathrm{SiO}_{4}$ species as gel structure [45, 46]. Some quartz and illite remain as crystalline phases in the geopolymers $\mathrm{G}, \mathrm{G}_{3}$ and $\mathrm{G}_{5}$ [47].

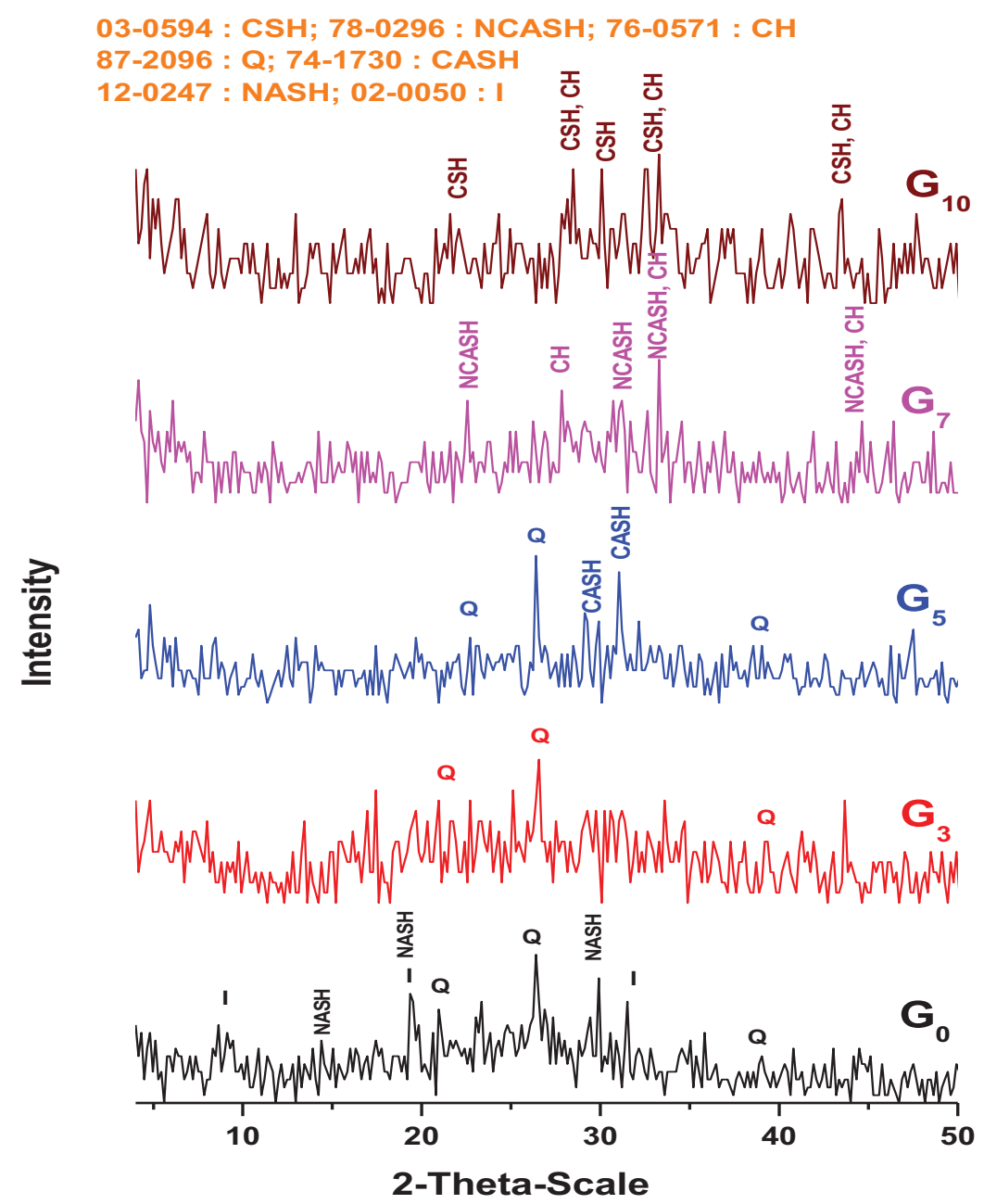

Fig. (8). XRD patterns of $\mathrm{G}, \mathrm{G}_{3}, \mathrm{G}_{5}, \mathrm{G}_{7}$ and $\mathrm{G}_{10}$ geopolymers cured for 28 days.

The Na-ASH gel structure is a charge-balanced aluminum silicate influence by $\mathrm{Si} / \mathrm{Al}$ ratio and alkali cations present. The mechanism of alkali-activated MK (geopolymers) involves poly condensation reaction of geopolymeric precursors i.e. aluminum silicate oxide with alkali poly-sialates forming polymeric $\mathrm{Si}-\mathrm{O}-\mathrm{Al}$ bond [48]. Many authors [49, 50] reported that the product of $\mathrm{MK}$ activation with $\mathrm{NaOH}$ in the presence of sodium silicate solutions is $\mathrm{Na}-\mathrm{ASH}$ gel with good mechanical properties as obtained in $\mathrm{G}$.

XRD patterns of $\mathrm{G}_{3}-\mathrm{G}_{7}$ have the same amorphous character as that pattern generated by $\mathrm{G}$ with some crystalline phase's inclusions. The alkaline activation of BFS leads to acceleration of polymerization and formation of some new phases that may help the geopolymeric gel for the development of its strength. It is well known that calcium silicate 
hydrate $(\mathrm{CSH})$ phases are the main binding phase in BFS alkali-activated materials having low $\mathrm{C} / \mathrm{S}$ ratio with varying degrees of crystallinity [51]. The presence of CSH and geopolymer gels has been reported previously in various systems containing $\mathrm{Ca}(\mathrm{OH})_{2}$ or slag as calcium sources $[52,53]$. Several new crystalline phases including CASH, NCASH and $\mathrm{Ca}(\mathrm{OH})$ are formed due to slag alkali-activated reactions. The peaks of quartz and illite are almost disappeared indicating a high degree of geopolymerisation. In $\mathrm{G}_{5}$, a reduced intensity of the amorphous hump $(2 \theta=25-35)$, associated with the formation of thomsonite CASH type gels is observed. The formation of CASH in the matrix forms a basic skeleton of percolating solids which determine the time for the onset of hardening. This quick hardening is not only attributed to CASH formation at an early age but is also due to the higher rate of geopolymerization. Yip et al. reported that the presence of calcium leads to precipitate $\mathrm{CASH}$ which acts as nucleation sites, and promotes the quick formation of geopolymer gel [54]. Yip's hypothesis also reported that the formation of $\mathrm{Ca}(\mathrm{OH})_{2}$ could potentially work as a nucleation site for geopolymer formation $[55,56]$. The formation of CASH also consumes water and consequently increases the alkalinity of system and further encourages the dissolution of MK particles [57]. This process raises the rate of poly condensation and aluminum silicate geopolymer formation. In $\mathrm{G}_{7}$, XRD pattern indicates the formation of Garronite (NCASH) and $\mathrm{Ca}(\mathrm{OH})_{2}$ phases with geopolymer. Garronite (NCASH) has also previously been detected in alkali-activated slag/metakaolin geopolymers produced from strong activator concentration [58, 59]. Garronite is consequently formed due to the transformation of gismondine; a highly calcium-rich member of zeolite family, to garronite via sodium-calcium ion exchange process in high concentrated alkaline medium [59, 60]. It is also probable that $\mathrm{Ca}(\mathrm{OH})_{2}$ being precipitated from the high alkalinity medium once the presence of soluble Ca ions at the early dissolution step [61]. In $\mathrm{G}_{10}$, XRD show that the main phases are $\mathrm{CSH}$ and $\mathrm{Ca}(\mathrm{OH})_{2}$ with low intensity. Once the Ca ions are dissolved from the starting materials (slag), they prefer to react with silicon ions to yield $\mathrm{CSH}$ which are rich in alkalis $[62,63]$. The formation of $\mathrm{CSH}$ is favored rather than $\mathrm{Ca}(\mathrm{OH})_{2}$ due to its lower solubility [64].

\subsubsection{FTIR of Geopolymers}

FTIR spectra of $G, G_{3}, G_{5}, G_{7}$ and $G_{10}$ geopolymers cured for 28 days are shown in Fig. (9). Significant broad bands of $\mathrm{OH}$ stretching and bending are observed in the range of 3430-3450 and $1650 \mathrm{~cm}^{-1}$. These are corresponding to adsorbed or cached water molecules in the large voids of polymeric skeleton allied with the reaction products [65, 66]. In FTIR spectra of $\mathrm{G}_{3}, \mathrm{G}_{5}, \mathrm{G}_{7}$ and $\mathrm{G}_{10}$, the bands located between 1420 and $1450 \mathrm{~cm}^{-1}$ are assigned to stretching vibrations of $\mathrm{O}-\mathrm{C}-\mathrm{O}$ bond indicating the existence of carbonate which is occurred due to atmospheric carbonation [67]. The presence of higher sodium carbonate content might interrupt the polymerization progression. Increasing contents of BFS also leads to the growth of the carbonate band at $1420 \mathrm{~cm}^{-1}$. The major band between 958 and $1023 \mathrm{~cm}^{-1}$ is atributed to asymmetric stretching vibration of $\mathrm{Si}-\mathrm{O}-\mathrm{T}$ bands, where $\mathrm{T}$ is tetrahedral silicon or aluminum. The band at about $1065 \mathrm{~cm}^{-1}$ Fig. (3) FTIR of metakaolin) corresponding to the Si-O asymmetric stretching in tetrahedral, is shifted to lower wave numbers (about $995-1023 \mathrm{~cm}^{-1}$ for $\mathrm{G}_{7}-\mathrm{G}$ ) after polymerization reaction as presented in Fig. (9). The shift indicates formation of new highly cross linked geopolymer gel frameworks. The great shift towards lower wave numbers might be due to the partial substitution of $\mathrm{SiO}_{4}$ tetrahedral by $\mathrm{AlO}_{4}$ tetrahedral, tend to change in the local chemical surroundings of $\mathrm{Si}-\mathrm{O}$ bond and newly formed aluminosilicate type gels. The strong shoulder peak for pure MK (seen in Fig. (3) located at $807 \mathrm{~cm}^{-1}$ that corresponds to Al-O and Si-O bending, moved to a higher frequency at $870 \mathrm{~cm}^{-1}$ after geopolymerization. This is an evidence for the presence of the larger amount of tetrahedral coordinated $\mathrm{AlO}_{4}$, formed by dissolution of $\mathrm{MK}[68,69]$. In $\mathrm{G}_{-} \mathrm{G}_{5}$, the band at $715 \mathrm{~cm}^{-1}$ is attributed to symmetric stretching vibrations of $\mathrm{Si}-\mathrm{O}-\mathrm{Si}(\mathrm{Al})$ bridges, while the bands at 553 and $470 \mathrm{~cm}^{-1}$ are ascribed to the symmetric stretching of $\mathrm{Al}-\mathrm{O}-\mathrm{Si}$ and to the bending of $\mathrm{Si}-\mathrm{O}-\mathrm{Si}$ and $\mathrm{O}-\mathrm{Si}-\mathrm{O}$ bonds [70], respectively. This shift to lower wavenumber points out the high level of replacement of $\mathrm{Al}$ instead of $\mathrm{Si}$ in tetrahedral. In previous works [71, 72], it is indicated that the formation of MK geoplymer in the presence of calcium supports the simultaneous development of cementitious gels $\mathrm{C}(\mathrm{A}) \mathrm{SH}$ and NASH type gels and decreasing the formation of geopolymeric gel [73, 74]. In these systems, $\mathrm{Ca}^{2+}$ is supposed to be coupled with the Si-O-Al framework of geopolymeric gel, participating in balancing of negative charge allied with tetrahedral $\mathrm{Al}$ (III) and replacing the alkali cations [75, 76]. This is consistent with the move of symmetric stretching vibrations of Si-O-( $\mathrm{Si}, \mathrm{Al}$ ) bridges to higher wavenumber (from 644 to $715 \mathrm{~cm}^{-1}$ ) with the increase of BFS, which implies the amendment of aluminosilicate structure compared with MK based geopolymers as a sequence of cation replacement in the non-framework sites [77]. This result confirms well with the result of XRD (Fig. 8). 


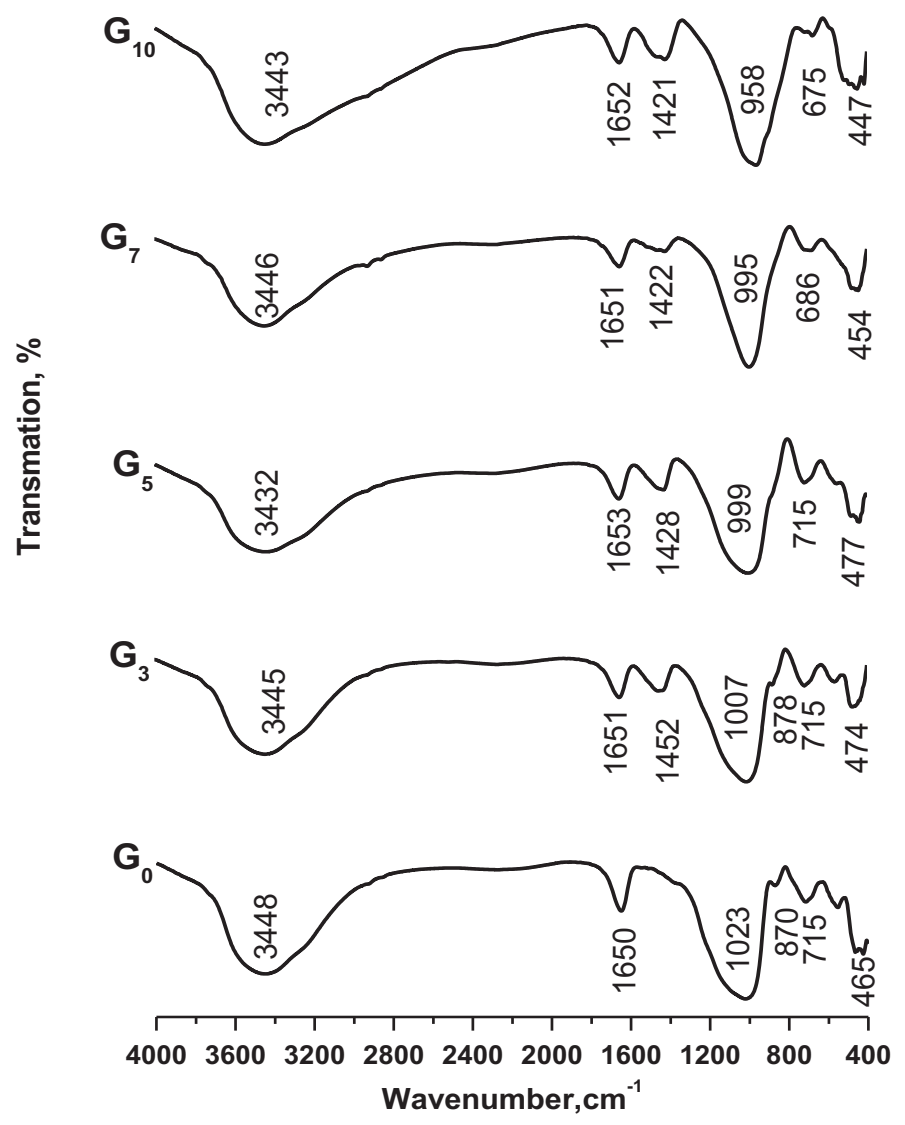

Fig. (9). FTIR spectrum of $\mathrm{G}, \mathrm{G}_{3}, \mathrm{G}_{5}, \mathrm{G}_{7}$ and $\mathrm{G}_{10}$ geopolymers cured for 28 days.

\subsubsection{SEM of Geopolymers}

SEM was used to analyze the morphology of starting material (MK) and microstructure of $G$ and $\mathrm{G}_{7}$ geopolymers curried at 28 days. SEM micrographs of MK indicate that the platelet hexagonal structure of kaolinite crystals are relatively disappeared and transferred to relatively amorphous structure with agglomeration due to calcination process at $850^{\circ} \mathrm{C}$ as shown in Fig. (10). The detected crystals are related to quartz and illite. Some of the particles are within the range of nano size.

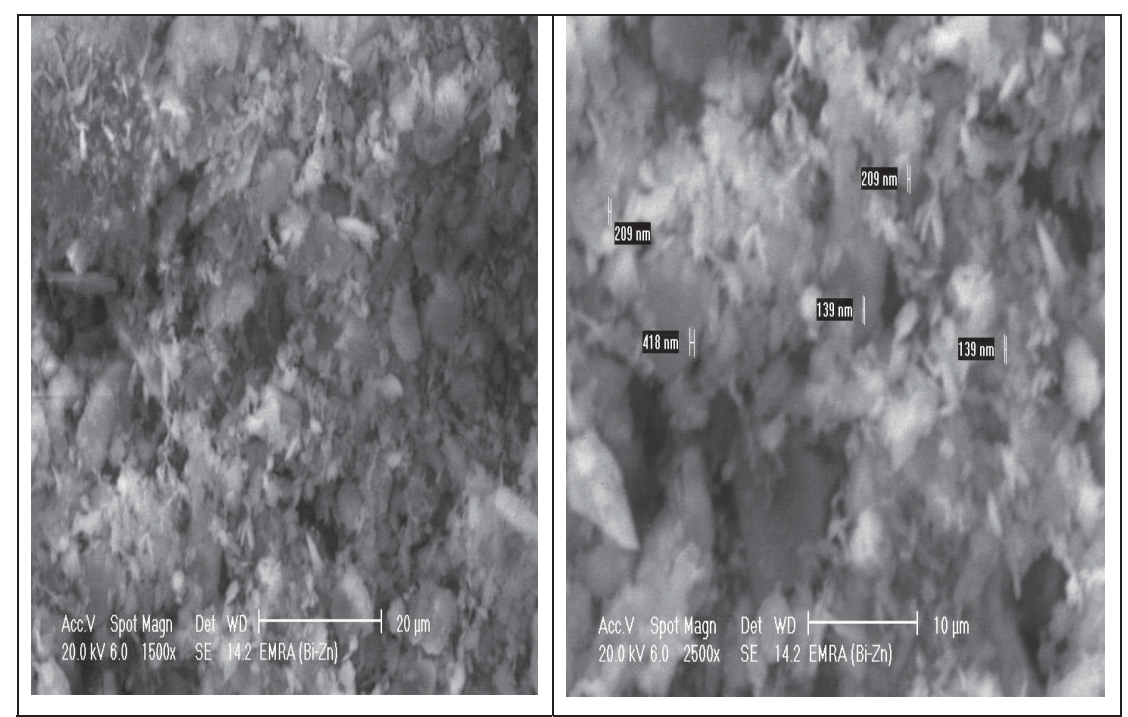

Fig. (10). SEM images of starting materials. 
Figs. (11 and 12) show SEM micrographs with EDAX analyses of $G$ and $G_{7}$, respectively. Remarkable differences in microstructure are observed for both samples. $G_{o}$ exhibits gel-like microstructure produced from geopolymer formation, with some flake-like layer structures similar to that of metakaolinte particulates. It is well known that the solid liquid reaction recognized a gel system with lower water amount, so it is logical to assume that the raw materials can keep their shape during the geopolymerization and molding processes. This is supported by SEM images shown in Fig. (11), which affords extra confirmation to the supposition that geopolymeric reaction is mainly occurred on the surface layer of the solid particulates [78, 79]. This interesting result suggests that the structure of geopolymer maintained partially the sheet of metakaolin after reaction. This crystalline phase can also arise from impurities in raw materials or the process of recrystallization. EDAX analysis of $\mathrm{G}$ indicates the presence of $\mathrm{Al}, \mathrm{Si}$ and $\mathrm{O}$ as the main component of the formed geopolymer.

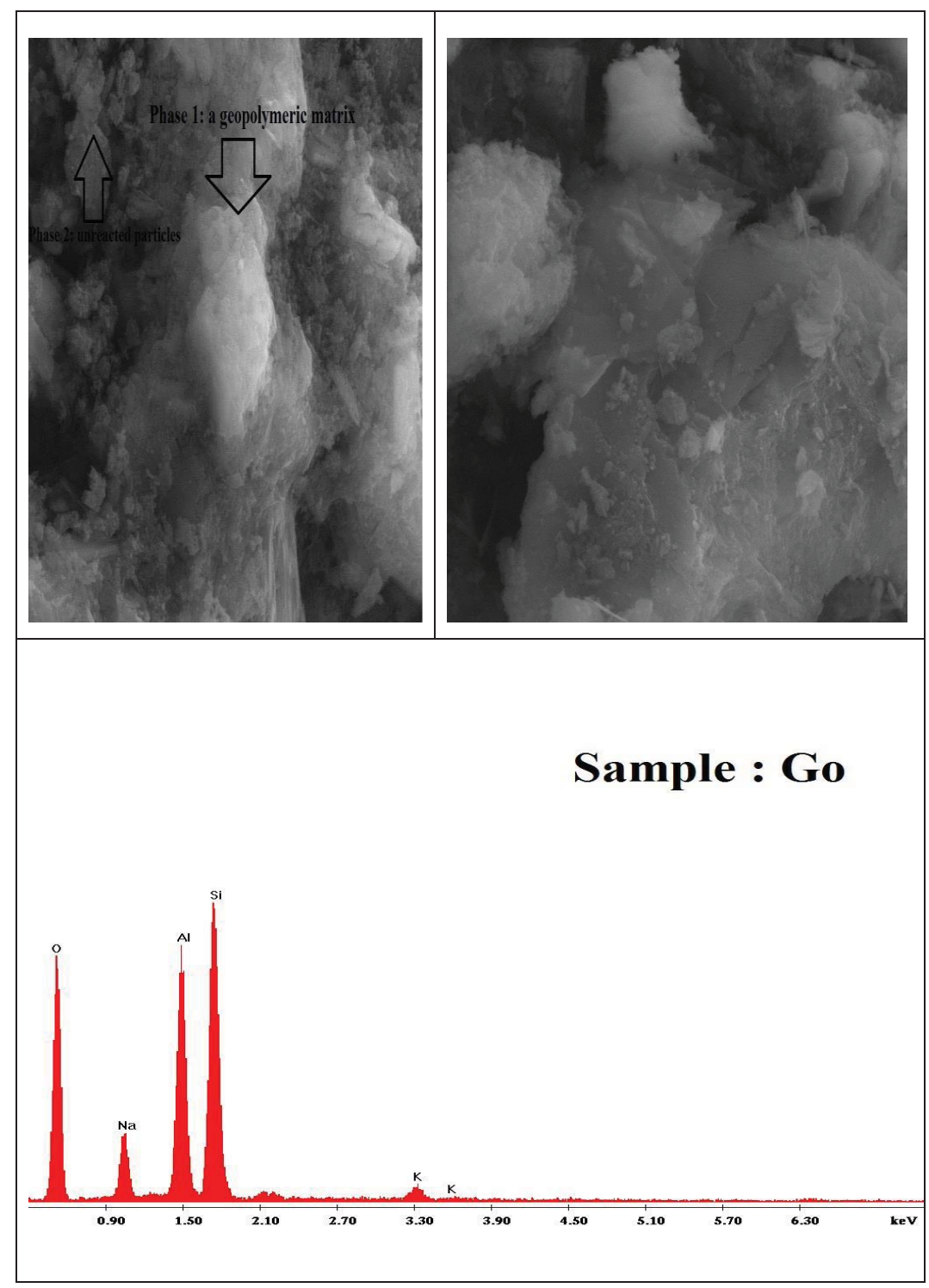

Fig. (11). SEM images and EDAX analysis of $\mathrm{G}_{0}$ geopolymer. 


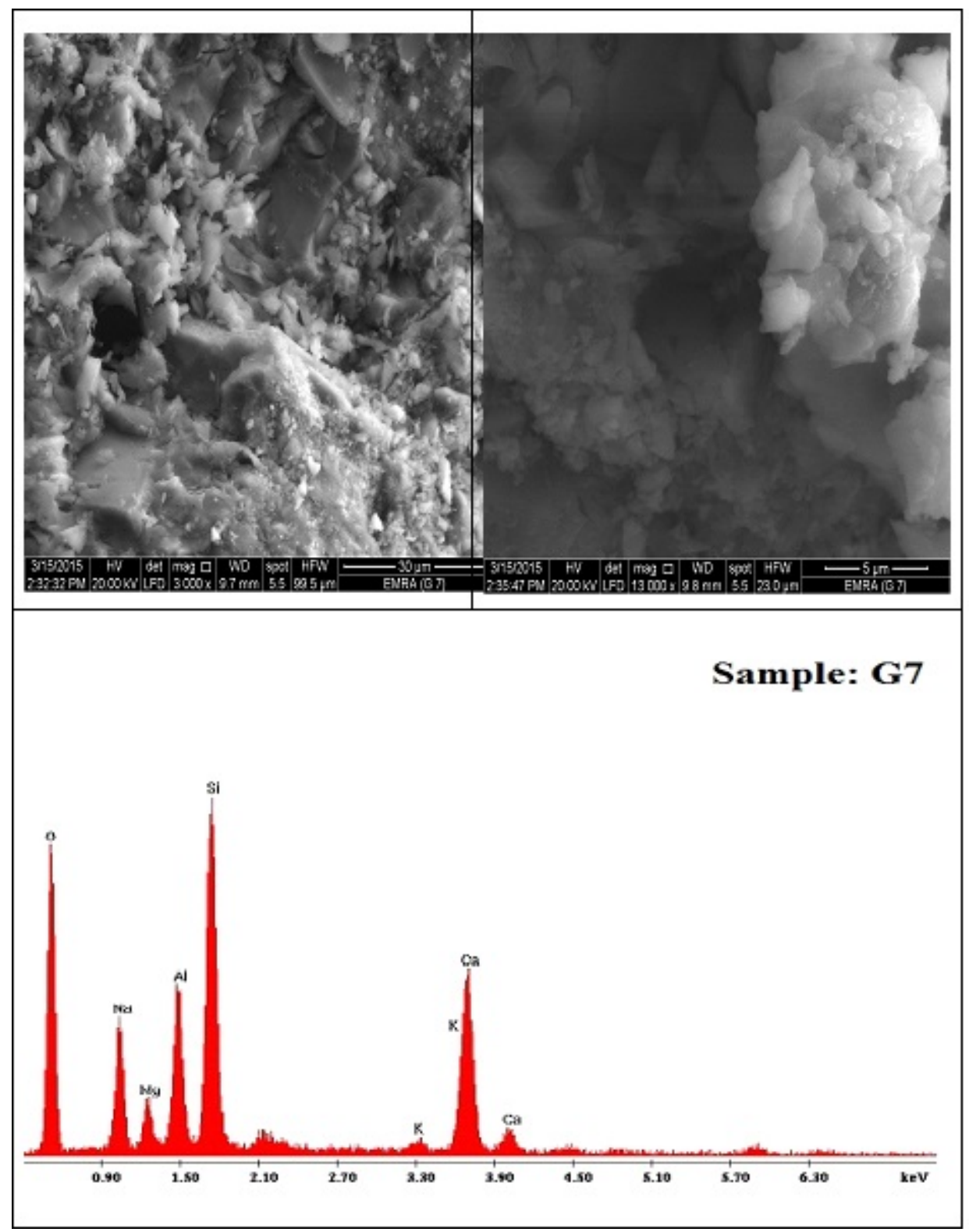

Fig. (12). SEM images and EDAX analysis of $\mathrm{G}_{7}$ geopolymer.

Fig. (12) shows SEM images and EDAX analysis of $\mathrm{G}_{7}$ geopolymer. Two individual phases are formed as a result of alkali activation of metakaolin in the presence of BFS i.e. geopolymeric gel, (C-A-S-H) gel and some remaining unreacted precursor. Metakaolin particle morphology doesn't vary obviously, but it is linked by a gel-like network. The occurrence of slag promotes connected gel-like structure geopolymer formation. This different feature of microstructure explains the higher hardening rate of $\mathrm{G}_{7}$ as compared with $\mathrm{G}$. At the early stage of reaction, as the calcium dissolves, $\mathrm{CASH}$ is formed in the microstructure. This phase can act as nucleation spot for geopolymerization, rising an intermixed microstructure of CASH and $\mathrm{NASH}$ at an early age [80, 81]. The $\mathrm{Ca} / \mathrm{Si}$ ratio of the CASH formed gel (ca. 0.49) is lower than that Portland cement (1.2 to 2.3). EDAX analysis of this sample indicates the presence of $\mathrm{Al}, \mathrm{Si}, \mathrm{Ca}$, $\mathrm{Na}, \mathrm{Mg}$ and $\mathrm{O}$ as the component of the predicted phases. Quantitative analysis of G0 and G7 are presented in Table [82].

In sample $\mathrm{G}_{7}$, the ratio of $\mathrm{Na} / \mathrm{Al}$ is 1.21 , and $\mathrm{Si} / \mathrm{Al}$ ratio is 2.21 . Thus, the main geopolymeric gel is inferred to be (Na)-poly(sialate-siloxo-), i.e. $\mathrm{Na}_{\mathrm{n}}-(-\mathrm{Si}-\mathrm{O}-\mathrm{Al}-\mathrm{O}-\mathrm{Si}-\mathrm{O}-)_{\mathrm{n}}-$, PSS type. On the other hand, the $\mathrm{Na} / \mathrm{Al}$ ratio in $\mathrm{G}$ system is slightly $<1$, which points out that only $\mathrm{Na}^{+}$as cation is not enough, so a partial calcium participant in geopolymerization is needed to obtain charge balance [83]. 


\section{CONCLUSION}

The following remarks are concluded:

- The addition of calcium-rich BFS into MK based geopolymers causes properties improvement and shorting in setting time by forming C-A-S-H gel in addition to N-A-S-H gel. Calcium-rich BFS accelerates the hardening process and decreases the alkaline liquid consistency.

- With increasing BFS content, the bulk density increases from $1.67-2.33 \mathrm{~g} / \mathrm{cm}^{3}$. Moreover, the bulk density increases with increasing curing time. This is due to the occurring of different chemical reactions which lead to different products and improvement of compressive strength.

- The prepared geopolymers contain two or three phases depending on whether BFS is added or not. For geopolymer with no BFS (G0), it contains two phases, namely; un-reacted metakaolin and geopolymer gel. For geopolymers with $\mathrm{CaO}$ sourced from BFS (G1-G10), three phases are formed, namely; un-reacted metakaolin, geopolymer gel and CASH gel.

- The optimum properties were achieved with mix containing $70 \%$ slag, after which the deterioration in properties was recorded.

\section{CONSENT FOR PUBLICATION}

Not applicable.

\section{CONFLICT OF INTEREST}

The authors declare no conflict of interest, financial or otherwise.

\section{ACKNOWLEDGEMENTS}

Declared none.

\section{REFERENCES}

[1] Davidovits J. Geopolymers: Inorganic polymeric new materials. J Therm Anal 1991; 37: $1633-56$. [http://dx.doi.org/10.1007/BF01912193]

[2] Duxson P, Fernandez-Jimenez A, Provis JL, et al. Geopolymer technology: The current state of the art. J Mater Sci 2007; 42(9): 2917-33. [http://dx.doi.org/10.1007/s10853-006-0637-z]

[3] Duxson P, Lukey GC, Separovic F, van Deventer JSJ. Effect of alkali cations on aluminum incorporation in geopolymeric gels. Ind Eng Chem Res 2005; 44(4): 832-9. [http://dx.doi.org/10.1021/ie0494216]

[4] Krivenko PV. Proceedings of the first international conference on alkalineCements and concretes. Kiev, Ukraine: VIPOL Stock Company 1994; pp. 11-129.

[5] Davidovits J. US Patent 4. 1982; pp. 349-86.

[6] Hos JP, McCormick PG, Byrne LT. Investigation of a synthetic aluminosilicate inorganic polymer. J Mater Sci 2002; 37: $2311-6$. [http://dx.doi.org/10.1023/A:1015329619089]

[7] Allahverdi A, Mehrpour K, Kani EN. Taftan Pozzolan-Based Geopolymer Cement. J Eng Sci 2008; 19 : 1-5.

[8] Xu H, van Deventer JSJ. Geopolymerisation of multiple minerals. Miner Eng 2002; 15: 1131-9. [http://dx.doi.org/10.1016/S0892-6875(02)00255-8]

[9] Kriven WM, Bell JL, Gordon M. Geopolymer refractories for the glass manufacturing industry. Ceram Eng Sci Proc 2004; 25 (24): 57-79. [http://dx.doi.org/10.1002/9780470294857.ch5]

[10] Lancellotti I, Kamseu E, Michelazzi M, Barbieri L, Corradi A, Leonelli C. Chemical stability of geopolymers containing municipal solid waste incinerator fly ash. Waste Manag 2010; 30(25): 673-79. [http://dx.doi.org/10.1016/j.wasman.2009.09.032]

[11] Andini S, Cioffi R, Colangelo F, Ferone C, Montagnaro F, Santoro L. Characterization of geopolymer materials containing MSWI fly ash and coal fly ash. Adv Sci Technol 2010; 69(26): 123-8. [http://dx.doi.org/10.4028/www.scientific.net/AST.69.123]

[12] Giancaspro JW, Papakonstantinou CG, Balaguru P. Flexural response of inorganic hybrid composites with E-glass and carbon fibers. J Eng Mater Technol 2010; 132(27): 1-8.

[13] Ferone C, Colangelo F, Cioffi R, Montagnaro F, Santoro L. Mechanical performances of weathered coal fly ash based geopolymer bricks. Procedia Eng 2011; 21: 745-52. 
[http://dx.doi.org/10.1016/j.proeng.2011.11.2073]

[14] Van Deventer JSJ, Provis JL, Duxson P. Technical and commercial progress in the adoption of geopolymer cement. Miner Eng 2012; 29: 89-104.

[http://dx.doi.org/10.1016/j.mineng.2011.09.009]

[15] Davidovits J. Geopolymer, chemistry and applications, $3^{\text {rd }}$ printing. In: Saint-Quentin, France: Institut Geopolymer 2008

[16] Konstantinos AK. Potential of geopolymer technology towards green buildings and sustainable cities. Procedia Eng 2011; 21 : 1023-32. [http://dx.doi.org/10.1016/j.proeng.2011.11.2108]

[17] Davidovits J. Geopolymers-inorganic polymeric new materials. J Therm Anal 1991; 37: 1633-56. [http://dx.doi.org/10.1007/BF01912193]

[18] Tchakoute Kouamo H, Elimbi A, Mbey JA, Ngally Sabouang CJ, Njopwouo D. The effect of adding alumina-oxide to metakaolin and volcanic ash on geopolymer products: A comparative study. Constr Build Mater 2012; 35: 960-9. [http://dx.doi.org/10.1016/j.conbuildmat.2012.04.023]

[19] Yip CK, Lukey GC, van Deventer JSJ. Effect of Blast Furnace Slag Addition on Microstructure and Properties of Metakaolinite Geopolymeric Materials. In: Bansal NP, Singh JP, Kriven WM, Schneider H, Ed. Advances in Ceramic Matrix Composites IX. Wiley: USA 2003; pp. 187-211.

[20] Liew YM, Kamarudin H, Mustafa Al Bakri AM, et al. Processing and characterization of calcined kaolin cement powder. Constr Build Mater 2012; 30: 794-802.

[http://dx.doi.org/10.1016/j.conbuildmat.2011.12.079]

[21] Boonserm K, Sata V, Pimraksa K, Chindaprasirt P. Improved geopolymerization of bottom ash by incorporating fly ash and using waste gypsum as additive. Cement Concr Compos 2012; 34: 819-24. [http://dx.doi.org/10.1016/j.cemconcomp.2012.04.001]

[22] Suwan T, Fan M. Influence of OPC replacement and manufacturing procedures on the properties of self-cured geopolymer. Constr Build Mater 2014; 73: 551-61. [http://dx.doi.org/10.1016/j.conbuildmat.2014.09.065]

[23] Suwan T, Fan M. Influence of OPC replacement and manufacturing procedures on the properties of self-cured geopolymer. Constr Build Mater 2014; 73: 551-61.

[http://dx.doi.org/10.1016/j.conbuildmat.2014.09.065]

[24] Stutzman P. Guide for X-Ray Powder Diffraction Analysis of Portland Cement and Clinker. NISTIR 1996.

[25] Struble L. The effects of water on maleic and salicylic acid extraction. Cem and Con Res 1985; 15(4): 631-6.

[26] Database M. Mineralogy Database Available from: http://www.webmineral.com/data//Kaolinite.shtml

[27] Bhaskar J. Saikia, gopalakrishnarao parthasarathy, fourier transform infrared spectroscopic characterization of kaolinite from assam and meghalaya, northeastern India. J Mod Phys 2010; 1: 206-10. [http://dx.doi.org/10.4236/jmp.2010.14031]

[28] Valeria FFB, MacKenzie KJD, Thaumaturgo C. Synthesis and characterisation of materials based on inorganic polymers of alumina and silica: sodiumpolysialate polymers. Int J Inorg Mater 2000; (2): 309-17.

[29] Farmer VC. The infrared spectra of minerals MineralogicalSociety Monogram 4, London (1974), 331. [http://dx.doi.org/10.1180/mono-4]

[30] Bernal SA, Provis JL, Rose V, Mejı'a de Gutie'rrez R. Evolution of binder structure in sodium silicate-activated slag metakaolin blends. Cement Concr Compos 2011; 33(1): 46-54. [http://dx.doi.org/10.1016/j.cemconcomp.2010.09.004]

[31] Xu H, Gong W. Larry S, Kevin I, Werner L, Ian L.P, Effect of blast furnace slag grades on fly ash based geopolymer waste forms. Fuel 2014; 133: $332-40$. [http://dx.doi.org/10.1016/j.fuel.2014.05.018]

[32] Phoo-ngernkham T, Chindaprasirt P, Sata V, Hanjitsuwan S, Hatanaka S. The effect of adding nano-SiO2 and nano- $\mathrm{Al}_{2} \mathrm{O}_{3}$ on properties of high calcium fly ash geopolymer cured at ambient temperature. Mater Des 2014; 55: 58-65.

[http://dx.doi.org/10.1016/j.matdes.2013.09.049]

[33] Chindaprasirt P, Rattanasak U. Utilization of blended Fluidized Bed Combustion (FBC) ash and Pulverized Coal Combustion (PCC) fly ash in geopolymer. Waste Manag 2010; 30(4): 667-72. [http://dx.doi.org/10.1016/j.wasman.2009.09.040] [PMID: 19854038]

[34] Chindaprasirt P, Chareerat T, Hatanaka S. CaO T. High-strength geopolymer using fine high-calcium fly ash. J Mater Civ Eng 2011; 23: 264-70.

[http://dx.doi.org/10.1061/(ASCE)MT.1943-5533.0000161]

[35] Xu H, Gong W, Gong W, et al. Effect of blast furnace slag grades on fly ash based geopolymer waste forms. Fuel 2014; 133 : 332-40. [http://dx.doi.org/10.1016/j.fuel.2014.05.018]

[36] Bernal SA, Provis JL, Walkley B, et al. Gel nanostructure in alkali-activated binders based on slag and fly ash, and effects of accelerated carbonation. Cement Concr Res 2013; 53: 127-44. 
[http://dx.doi.org/10.1016/j.cemconres.2013.06.007]

[37] Ismail I, Bernal SA, Provis JL, San Nicolas R, Hamdan S, van Deventer JSJ. Modification of phase evolution in alkali-activated blast furnace slag by the incorporation of fly ash. Cement Concr Compos 2014; 45: 125-35.

[http://dx.doi.org/10.1016/j.cemconcomp.2013.09.006]

[38] Kumar S, Kumar R, Mehrotra SP. Influence of granulated blast furnace slag on the reaction, structure and properties of fly ash based geopolymer. J Mater Sci 2010; 45: 607-15. [http://dx.doi.org/10.1007/s10853-009-3934-5]

[39] Susan A, Bernal Erich D, Ruby Mejı 'a de Gutie'rrez, Rodrı guez, Susan A, Provis John L. Mechanical and thermal characterisation of geopolymers based on silicate-activated metakaolin/slag blends. J Mater Sci 2011; 46: 5477-86. [http://dx.doi.org/10.1007/s10853-011-5490-z]

[40] J. Davidovits, Properties of Geopolymer Cements. In: Krivenko P.V. (Ed.), Proceedings of First International Conference on Alkaline Cements and Concretes, Kiev, Ukraine, 1, 1994, pp. 131-149.].

[41] Li C, Sun H, Li L. A review: The comparison between alkali-activated slag ( $\mathrm{Si}+\mathrm{Ca})$ and metakaolin ( $\mathrm{Si}+\mathrm{Al})$ cements. Cement Concr Res 2010; 40: 1341-9.

[http://dx.doi.org/10.1016/j.cemconres.2010.03.020]

[42] Yip CK, Van Deventer JSJ. Effect of granulated blast furnace slag on geopolymerisation. CD-ROM Proceedings of 6th World Congress of Chemical Engineering. Melbourne, Australia. 2001.

[43] Rattanasak U, Pankhet K, Chindaprasirt P. Effect of chemical admixtures on properties of high-calcium fly ash geopolymer. Int J Miner Metall Mater 2011; 18(3): 364-9.

[http://dx.doi.org/10.1007/s12613-011-0448-3]

[44] Granizo ML, Alonso S, Blanco-Varela MT, Palomo A. Alkaline Activation of Metakaolin: Effect of Calcium Hydroxide in the Products of Reaction. J Am Ceram Soc 2002; 85: 225. [http://dx.doi.org/10.1111/j.1151-2916.2002.tb00070.x]

[45] Mackenzie KJD, Komphanchai S, Vagana R. Formation of inorganic polymers (geopolymers) from 2:1 layer lattice aluminosilicates. J Eur Ceram Soc 2008; 28: 177. [http://dx.doi.org/10.1016/j.jeurceramsoc.2007.06.004]

[46] De Silva P, Sagoe-Crenstil K, Sirivivatnanon V. Kinetics of geopolymerization: Role of $\mathrm{Al}_{2} \mathrm{O}_{3}$ and $\mathrm{SiO}_{2}$. Cement Concr Res 2007 ; 37 : 512. [http://dx.doi.org/10.1016/j.cemconres.2007.01.003]

[47] Bell JL, Sarin P, Driemeyer PE, et al. X-ray pair distribution function analysis of a metakaolin-based, KA1Si2O6 center dot 5.5H(2)O inorganic polymer (geopolymer). J Mater Chem 2008; 18: 5974-81.

[http://dx.doi.org/10.1039/b808157c]

[48] Zawrah MF, S. Farag Rabei, Kohail MH. Improvement of physical and mechanical properties of geopolymer through addition of zircon, Materials Chemistry and Physics. 15 September 2018; 217. [http://dx.doi.org/10.1016/j.matchemphys.2018.06.024]

[49] Granizo ML, Blanco MT, Puertas F, Palomo A. Alkaline activation of metacaolin: Influence of synthesis parameters, Proceeding of the Tenth International Congress on Chemistry of Cement. Göteborg 1997; 3.

[50] Granizo ML, Alonso S, Blanco-Varela MT, Palomo A. Alkaline activation of metakaolin: Effect of calcium hydroxide in the products of reaction. J Am Ceram Soc 2002; 85(1): 225-31. [http://dx.doi.org/10.1111/j.1151-2916.2002.tb00070.x]

[51] Pacheco-Torgal F, Castro-Gomes J, Jalali S. Alkali-activated binders: A review. Part 1. Historical background, terminology, reaction mechanisms and hydration products. Constr Build Mater 2008; 22: 1305-14.

[http://dx.doi.org/10.1016/j.conbuildmat.2007.10.015]

[52] Pacheco-Torgal F, Castro-Gomes J, Jalali S. Alkali-activated binders: A review. Part 1. Historical background, terminology, reaction mechanisms and hydration products. Constr Build Mater 2008; 22: 1305-14. [http://dx.doi.org/10.1016/j.conbuildmat.2007.10.015]

[53] Yip CK, van Deventer JSJ. Microanalysis of calcium silicate hydrate gel formed within a geopolymeric binder. J Mater Sci 2003; 38(18): 3851-60. [http://dx.doi.org/10.1023/A:1025904905176]

[54] Christina K, Yip Grant C, Lukey John L, et al. Effect of calcium silicate sources on geopolymerisation. Cement Concr Res 2008; 38 : 554-64. [http://dx.doi.org/10.1016/j.cemconres.2007.11.001]

[55] Yip CK, Lukey GC, van Deventer JSJ. The coexistence of geopolymeric gel and calcium silicate hydrate at the early stage of alkaline activation. Cement Concr Res 2005; 35: 1688-97. [http://dx.doi.org/10.1016/j.cemconres.2004.10.042]

[56] Zhang YJ, Wang YC, Xu DL, Li S. Mechanical performance and hydration mechanism of geopolymer composite reinforced by resin. Mater Sci Eng A 2010; 527(24-25): 6574-80. [http://dx.doi.org/10.1016/j.msea.2010.06.069] 
[57] Bernal SA, Provis JL, Rose V, Mejía de Gutiérrez R. High-resolution X-ray diffraction and fluorescence microscopy characterization of alkali-activated slag-metakaolin binders. J Am Ceram Soc 2013; 96(6): 1951-7. [http://dx.doi.org/10.1111/jace.12247]

[58] Ismail I, Bernal SA, Provis JL, San Nicolas R, Hamdan S, van Deventer JSJ. Modification of phase evolution in alkali-activated blast furnace slag by the incorporation of fly ash. Cement Concr Compos 2014; 45: 125-35. [http://dx.doi.org/10.1016/j.cemconcomp.2013.09.006]

[59] Zhang YJ, Wang YC, Xu DL, Li S. Mechanical performance and hydration mechanism of geopolymer composite reinforced by resin. Mater Sci Eng A 2010; 527: 6574-80. [http://dx.doi.org/10.1016/j.msea.2010.06.069]

[60] Bernal SA, Provis JL, Rose V, Mejía de Gutierrez R. Evolution of binder structure in sodium silicate-activated slag-metakaolin blends. Cement Concr Compos 2011; 33(1): 46-54. [http://dx.doi.org/10.1016/j.cemconcomp.2010.09.004]

[61] Yip CK, van Deventer JSJ. Microanalysis of calcium silicate hydrate gel formed within a geopolymeric binder. J Mater Sci 2003; 38(18): 3851-60.

[http://dx.doi.org/10.1023/A:1025904905176]

[62] Shi C, Krivenko PV, Roy DM. Alkali-Activated Cements and Concretes. Abingdon, UK: Taylor and Francis 2006. [http://dx.doi.org/10.4324/9780203390672]

[63] García-Lodeiro I, Palomo A, Fernández-Jiménez A, Macphee DE. Compatibility studies between N-A-S-H and C-A-S-H Gels. Study in the ternary diagram $\mathrm{Na}_{2} \mathrm{O}-\mathrm{CaO}-\mathrm{Al}_{2} \mathrm{O}_{3}-\mathrm{SiO}_{2}-\mathrm{H}_{2} \mathrm{O}$. Cement Concr Res 2011; 41(2): 923-31. [http://dx.doi.org/10.1016/j.cemconres.2011.05.006]

[64] Lloyd RR, Provis JL, van Deventer JSJ. Microscopy and microanalysis of inorganic polymer cements 2: The gel binder. J Mater Sci 2009; 44(2): 620-31. [http://dx.doi.org/10.1007/s10853-008-3078-z]

[65] Temuujin J, van Riessen A, Williams R. Influence of calcium compounds on the mechanical properties of fly ash geopolymer pastes. J Hazard Mater 2009; 167(1-3): 82-8. [http://dx.doi.org/10.1016/j.jhazmat.2008.12.121] [PMID: 19201089]

[66] García-Lodeiro I, Fernández-Jiménez A, Palomo A, Macphee DE. Effect of calcium additions on N-A-S-H cementitious gels. J Am Ceram Soc 2010; 1940(7): 1934-40.

[67] Puligilla S, Mondal P. Role of slag in microstructural development and hardening of fly ash-slag geopolymer. Cement Concr Res 2013; 43: 70-80.

[http://dx.doi.org/10.1016/j.cemconres.2012.10.004]

[68] Ben Haha M, Lothenbach B, Le Saout G, Winnefeld F. Influence of slag chemistry on the hydration of alkali-activated blast-furnace slag Part II: Effect of $\mathrm{Al}_{2} \mathrm{O}_{3}$. Cement Concr Res 2012; 42: 74-83. [http://dx.doi.org/10.1016/j.cemconres.2011.08.005]

[69] Zawrah MF, Khattab RM, Saad EM, Gado RA. Effect of Surfactant Types and Their Concentration on the Structural Characteristics of Nanoclay. Spectrochimica Acta, Part A: Molecular and Biomolecular Spectroscopy 2014; 122: 616-23. [http://dx.doi.org/10.1016/j.saa.2013.11.076]

[70] Lecomte I, Henrist C, Liegeois M, Maseri F, Rulmont A, Cloots R. (Micro)-structural comparison between geopolymers, alkali-activated slag cement and Portland cement. J Eur Ceram Soc 2006; 26: 3789-97.

[http://dx.doi.org/10.1016/j.jeurceramsoc.2005.12.021]

[71] Lee WKW, van Deventer JSJ. Use of infrared spectroscopy to study geopolymerization of heterogeneous amorphous aluminosilicates. Langmuir 2003; 19(21): 8726-34. [http://dx.doi.org/10.1021/la026127e]

[72] Alonso S, Palomo A. Alkali activation of metakaolin and calcium hydroxide mixtures: Influence of temperature, activator concentration and solids ratio. Mater Lett 2001; 47(2): 55-62. [http://dx.doi.org/10.1016/S0167-577X(00)00212-3]

[73] Bernal SA, Provis JL, Rose V, Mejı'a de Gutie'rrez R. Evolution of binder structure in sodium silicate-activated slagmetakaolin blends. Cement Concr Compos 2011; 33(1): 46-54. [http://dx.doi.org/10.1016/j.cemconcomp.2010.09.004]

[74] Bernal SA, Rodrı'guez ED, Mejı'a de Gutie'rrez R, Gordillo M, Provis JL. Mechanical and thermal characterization of geopolymers based on silicate-activated metakaolin/slag blends. J Mater Sci 2011; 46(16): 5477-86. [http://dx.doi.org/10.1007/s10853-011-5490-z]

[75] Garc1'a-Lodeiro I, Macphee DE, Macphee DE, Palomo A, Ferna'ndez J. Effect of alkalis on fresh C-S-H gels. FTIR analysis. Cement Concr Res 2009; 39: 147-53

[http://dx.doi.org/10.1016/j.cemconres.2009.01.003]

[76] Garcı'a-Lodeiro I, Ferna'ndez Jime'nez A, Palomo A, Macphee DE. Effect on fresh C-S-H gels of simultaneous addition of alkali and aluminum. Cement Concr Res 2010; 40: 27-32. [http://dx.doi.org/10.1016/j.cemconres.2009.08.004] 
[77] Provis JL, Yong SL, Duxson P, van Deventer JSJ. Geopolymer structures and kinetics: What have we learnt lately? $3^{\text {rd }}$ International Symposium on Non-Traditional Cement and Concrete. Brno, Czech Republic. 2008; pp. 589-97.

[78] Susan A Bernal, Erich D Rodri'guez, Gutie'rrez Ruby Mejia de, Provis John L, Delvasto Provis Silvio. Activation of Metakaolin/Slag Blends Using Alkaline SolutionsBased on Chemically Modified Silica Fume and Rice Husk Ash, Waste Biomass Valor [http://dx.doi.org/10.1016/S1466-6049(00)00041-6]

[79] Valeria FFB, Kenneth JDM, Clelio T. Synthesis and characterization of materials based on inorganic polymers of alumina and silica: Sodium polysialate polymers. Int J Inorg Mater 2000; 2: 309-17. [http://dx.doi.org/10.1016/S1466-6049(00)00041-6]

[80] Wang RH, Li H, Yan F. Synthesis and mechanical properties of metakaolinite-based geopolymer. Colloids Surf A Physicochem Eng Asp 2005; 268: 1-6.

[http://dx.doi.org/10.1016/j.colsurfa.2005.01.016]

[81] Zawrah MF, Gado RA, Feltin N, Ducourtieux S, Devoille L. Recycling and utilization assessment of waste firedclay bricks (Grog) with granulated blast-furnaceslag for geopolymer production. Process Saf Environ Prot 2016; 103: 237-51. [http://dx.doi.org/10.1016/j.psep.2016.08.001]

[82] Puligilla S, Mondal P. Role of slag in microstructural development and hardening of fly ash-slag geopolymer. Cement Concr Res 2013; 43: $70-80$. [http://dx.doi.org/10.1016/j.cemconres.2012.10.004]

[83] Guo X, Shi H, Warren AD. Compressive strength and microstructural characteristics of class C fly ash geopolymer. Cement Concr Compos 2010; 32: 142-7.

[http://dx.doi.org/10.1016/j.cemconcomp.2009.11.003]

(C) 2018 Zawrah et al.

This is an open access article distributed under the terms of the Creative Commons Attribution 4.0 International Public License (CC-BY 4.0), a copy of which is available at: (https://creativecommons.org/licenses/by/4.0/legalcode). This license permits unrestricted use, distribution, and reproduction in any medium, provided the original author and source are credited. 